\title{
Collateral Damage: How the COVID-19 Pandemic Has Affected the Dying Process of Palliative Care Patients in Hospitals-Our Experience and Recommendations
}

\section{Dear Editor,}

On 2 January 2020, Singapore implemented preventive measures to minimise importation of COVID-19 cases after China reported its first case to the World Health Organisation on 31 December 2019, in what was to become a global pandemic. After confirming its first local case of COVID-19 on 23 January 2020, Singapore has adopted increasingly stringent containment measures, moving into mitigation mode when the number of cases escalated. ${ }^{1,2}$ Local hospitals have also instituted progressively stricter restrictions on visitation hours and the number of visitors. As of 28 May 2020, there were 33,249 confirmed cases of COVID-19, with 14,925 cases under observation, 18,294 cases discharged, 7 patients in critical condition and 23 deaths attributed to COVID-19. ${ }^{3}$

To date, there have been no studies on the needs of families of palliative care patients who do not have COVID-19 but are dying in the hospital during this pandemic. One local study done years before this pandemic had found that the families of dying patients wished to be present for the final moments to bid a last farewell. ${ }^{4}$ Palliative Care is an approach that improves the quality of life of patients and their families facing problems associated with life-threatening illnesses, by treating symptoms such as pain, and addressing other physical, psychosocial and spiritual issues. ${ }^{5}$ As a palliative care consult team in a 1,000-bed general hospital, we seek to highlight our experience and recommendations.

\section{Two Vignettes on Dying Patients in the Palliative Care Service}

Mrs A had multiple co-morbidities on a background of end-stage renal failure and had been undergoing haemodialysis for more than 10 years. She was delirious and in septic shock, and was unable to tolerate further dialysis. Due to the pandemic, COVID-19 negative patients like her could no longer have visitors unless the medical team granted special permission. Even then, only one visitor was permitted within restricted hours. As Mrs A became terminally ill with her life expectancy whittled down to days, her son and daughter took turns to see her while wearing surgical masks.

Mr B had terminal cancer of the colon complicated by pneumonia who was negative for COVID-19, and he was severely hypotensive. He was only allowed 1 visitor. His family opted to terminally discharge him home so that he could be surrounded by his loved ones at his deathbed. However, as most of the ambulances in the country were diverted to ferry suspected or COVID-19 patients, his ambulance took longer to arrive. $\mathrm{Mr} \mathrm{B}$ passed on while waiting in the hospital, accompanied by only 1 family member.

\section{Dying in the Time of COVID-19}

Patients and their relatives were unhappy in hospital during the Severe Acute Respiratory Syndrome (SARS) crisis because of restrictive rules and stringent visitor limitations. ${ }^{6}$

\section{Separation}

In a pandemic where only 1 visitor or none is allowed into the hospital, many palliative care patients are anguished by the lack of visitors. They display emotional pain which sometimes manifests as "total pain". Some adapt by making video calls to their loved ones. Those who are technologically challenged or too weak remain unconnected.

Families express frustration when they cannot contact or visit the patient. Family members who have COVID-19 or are quarantined cannot visit even if the patient turns ill. They have to rely on verbal reports by the healthcare team or the designated visitor. Most remain worried that the patient's physical, mental, emotional and spiritual needs will be unmet without their presence. Some fear that the patient will be unable to convey needs or discomfort to nurses who do not speak their language. Many panic whenever they receive calls from the hospital.

\section{Masking}

Visitors have to wear surgical masks and patients can no longer see the entire face of their loved ones. 
Those with altered mental state have difficulty recognising their family members in masks.

During the SARS crisis in 2003, families expressed dismay at the gulf created by the use of personal protective equipment. ${ }^{7}$ Currently, families still feel that the mask creates a communication barrier. They perceive a loss of intimacy and are upset when the patient fails to identify them. Some of them surreptitiously remove their mask, increasing the risk of an infected visitor passing COVID-19 to the patient.

\section{Preferred Place of Death}

In many countries, patients prefer to die at home. ${ }^{8,9}$ In Singapore, home is also the preferred place of death for both cancer patients and their relatives. ${ }^{10}$ A recent study showed that patients and caregivers felt that patients on cancer treatment should not receive palliative care, ${ }^{11}$ implying that they are only open to palliative care options such as terminal discharge when treatment is not feasible. Terminal discharge is done when death is imminent and the patient is given a fast-track discharge from the hospital to be conveyed home via ambulance. Our team coordinates with the home hospice team to visit the patient and provide support on an urgent basis.

During this COVID-19 pandemic, some patients and families who previously wanted to die in an institution change their minds, triggered by the severe limitation of visitors allowed while dying. They now wish for terminal discharge so that more visitors can see the patient at home. Thus, the number of terminal discharges have risen and home hospice teams have more urgent cases to see.

Since many ambulances have been deployed to handle COVID-19 patients, terminal discharge cases have to wait longer for the ambulance transport home. Some die without reaching home and without family by their side.

\section{Disrupted Bereavement}

Many patients wish to receive support from family at the end of their lives. ${ }^{12}$ Given the visitor restrictions, families can no longer bid farewell to the dying patient in hospital. ${ }^{7}$ As only one visitor is permitted, this visitor will be left to grieve alone should the patient die on his watch. During the transition between visitors, the patient risks dying alone. Only 1 visitor can claim the body after death, which compounds the grief and bereavement.

\section{Recommendations for Palliative Care Teams}

\section{Early Discussion of Discharge Planning}

Terminal discharge is logistically complex, involving the procurement of equipment such as oxygen concentrators or hospital beds at short notice. Arrangements also have to be made for services such as private nursing aides. Therefore, early discharge planning is essential for a smooth transition home. This also minimises distress to the family.

\section{New Terminal Discharge Protocol Expedited}

Although terminal discharges were usually effected within 1 to 2 hours, the COVID-19 pandemic introduced new impediments. We designed a new protocol that comes with separate checklists for the doctors and the nurses (Fig. 1), and collaborated with the hospital pharmacy to issue a pre-packed box of standby medications and medical supplies when required.

\section{Preparing for Care of the Patient at Home}

Caregivers undergo training for medication administration before the patient is discharged, and are given printed instructions with diagrams on the use of the medications.

We offer pre-filled syringes of prescribed amounts of standby subcutaneous medications, negating the need to break ampoules of medication to draw into syringes for injection. This reduces psychological stress, risk of needlestick injuries and medication errors. Some patients are discharged with a subcutaneous cannula. Subcutaneous medications can be administered by the caregiver without puncturing the patient's skin.

We brief the home hospice team-summarising the inpatient stay, highlighting potential symptoms, psychosocial problems or anticipated complicated grief. This ensures timely follow-up on issues (e.g., psychological care) for a seamless transition between the acute and community care teams. ${ }^{13}$

\section{Planning Ahead for the Ride Home}

During this pandemic, our patients wait longer for unplanned ambulance transport home. Therefore, we suggest planning at least one day in advance for terminal discharge to secure the ambulance booking.

Strategies to Improve Communication Between Patients and Families

Electronic devices such as mobile phones, electronic tablets and laptops are helpful aids in communication 


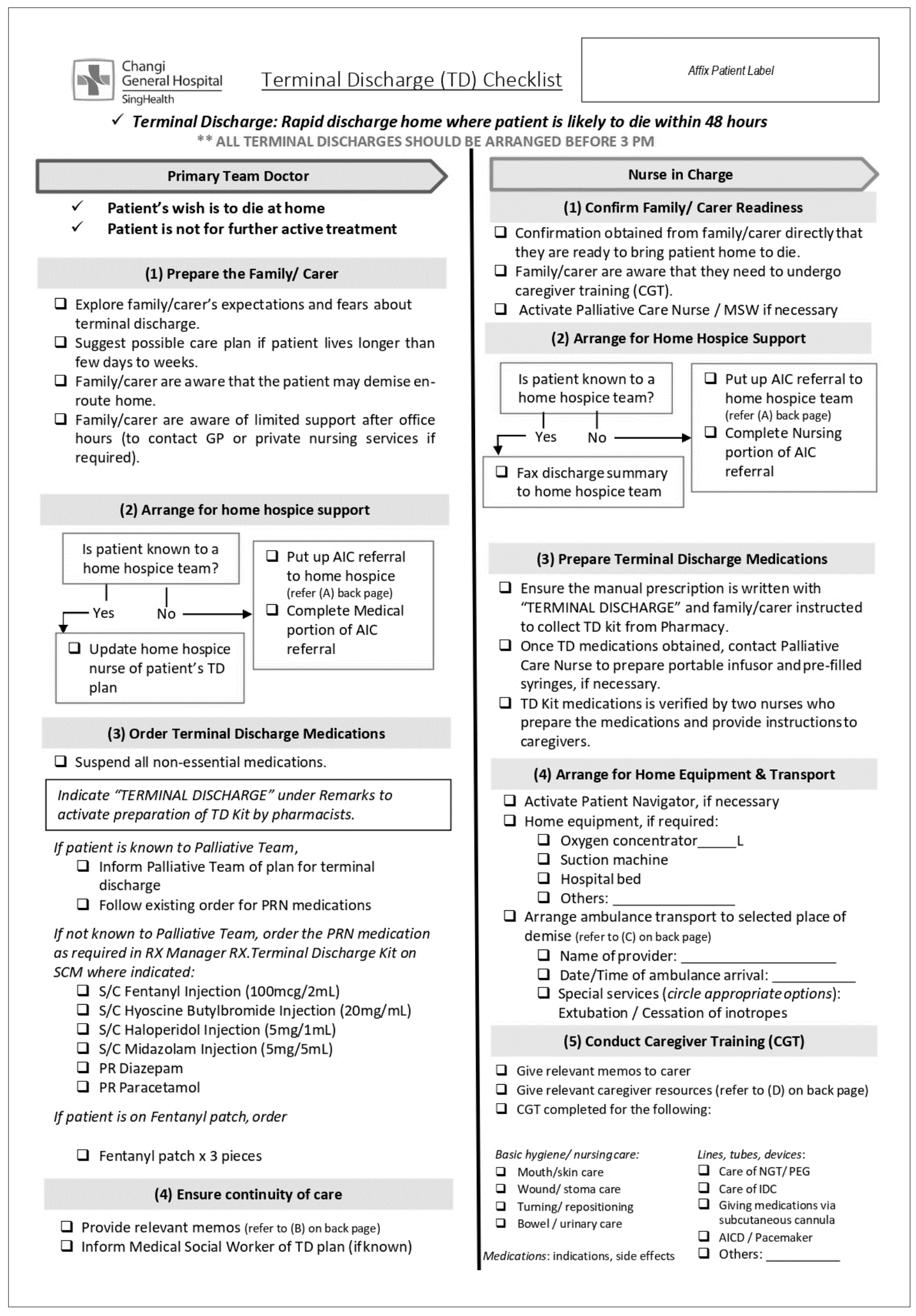


** ALL TERMINAL DISCHARGES SHOULD BE ARRANGED BEFORE 3 PM

- This is to facilitate same-day review of patients by home hospice nurses or by the next working day, and to ensure that there is adequate time to prepare the family.

- There is no home care support for new cases on weekends and publicholidays.

(A) Home Hospice Care Services available in Singapore:

$\begin{array}{lrr}\text { Assisi Hospice } & \text { Fax: } 62535312 & \text { Tel: } 68322650 \\ \text { Buddhist Compassion Relief Tzu Chi Foundation Fax: } 62626443 & \text { Tel: } 65702330 \\ \text { HCA Hospice Care } & \text { Fax: } 62911076 & \text { Tel: } 62512561 \\ \text { Metta Hospice Care** } & \text { Fax: } 67877542 & \text { Tel: } 65804695 \\ \text { MWS Home Hospice } & \text { Fax: } 64350274 & \text { Tel: } 64350270 \\ \text { Singapore Cancer Society } & \text { Fax: } 62219575 & \text { Tel: } 64215832 \\ \text { Tsao Foundation } & \text { Fax: } 65939522 & \text { Tel: } 65939500 \\ y \text { available in parts of East or North-East Singapore } & \end{array}$

** Only available in parts of East or North-East Singapore

\section{(B) Memos to be provided by primary team doctor}

1. Family physician / GP

- Non-coroner's case - state CCOD

- Coroner's case - To call police in event of demise. Indicate in bold at the top of the discharge summary that this is a coroner's case, not to sign up CCOD; not to remove foreign devices from body.

** Please note that terminal discharge for coroner's cases is discouraged.

2. Ambulance personnel - state DDIL status; not to return to hospital if demise occurs en-routehome

3. Home hospice team / private nurse - discharge summary; instructions for continuityof care at home

Where applicable:

- Immigration / ICA - carriage of cross-border controlled drugs

- Family - letter to be given to employers for compassionate leave

\begin{tabular}{|lll|}
\hline (C) & List of Private Ambulance & Services provided \\
\hline 1 & $\begin{array}{l}\text { Civic Ambulance Services Pte Ltd } \\
\text { Tel: } 63333000\end{array}$ & $\begin{array}{l}\text { Ambulance service } \\
\text { Sales/rental of medical equipment }\end{array}$ \\
\hline 2 & Life Care Ambulance \& Services & Ambulance service \\
& Tel: 62562522 / 96928920 & $\begin{array}{l}\text { Sales/rental of medical equipment } \\
\text { Overseas and cross border transport }\end{array}$ \\
\hline 3 & Hope Ambulance & Ambulance service \\
& $\begin{array}{l}\text { Tel: } 61001911 \\
\text { Tel: } 61002922\end{array}$ & $\begin{array}{l}\text { Terminal extubation / ventilator support } \\
\text { Cessation of inotropic support }\end{array}$ \\
& & $\begin{array}{l}\text { Overseas and cross border transport / Air ambulance } \\
\text { International Assistance }\end{array}$ \\
\hline 4 & Heng-Gref International Assists & Ambulance service \\
& Tel: 62726018 & Terminal extubation / ventilator support \\
& & Cessation of inotropic support \\
& & Overseas and cross border transport \\
\hline
\end{tabular}

This list is provided for reference only. Family members are not obliged to use the services from this list and are free to source for alternative agencies. The above are included in the $\mathrm{MOH}$ List of Approved Private Ambulance Operators.

\section{(D) List of resources to be printed out for family/carer}

$\square$ Terminal Discharge: Frequently Asked Questions (FAQ) for Caregivers

$\square$ Terminal discharge Kit - Instructions for Caregivers

- Subcutaneous medication administration via cannula

Caregiver training checklist - Performing administration of subcutaneous medication via cannula

Figure 1: Legend

AIC: Agency for Integrated Care; AICD: Automatic Implantable Cardioverter Defibrillator; CCOD: Certificate of Cause Of Death; DDIL: Terminally Ill; GP: General Practitioner; HCA: Hospice Care Association; ICA: Immigration and Checkpoints Authority; PEG: Percutaneous Endoscopic Gastrostomy; MWS: Methodist Welfare Services; NGT: Nasogastric Tube; PR: Per Rectal; RX Manager RX: a software program for electronic prescriptions for discharge medications; S/C: Subcutaneous; SCM: Sunrise Clinic Manager (a software platform for holding electronic medical records) 
while in hospital. Hospitals should be equipped with good Wi-Fi connection to enable tech-savvy patients and their families to tap on to these tools, and keep a supply of chargers and cables should the patients need to borrow them. Hospital staff can volunteer to facilitate the use of these devices in less savvy patients and families to enhance the quality of life for patients. ${ }^{14}$

\section{Teaching Healthcare Workers and Families how to Communicate Despite a Mask}

Families perceive a barrier to communication with the dying patient while wearing masks. There also is a negatively perceived lack of empathy from masked healthcare workers. ${ }^{15}$ We suggest harnessing other means of communication by use of body language, expressive eye contact, physical touch with clean hands (with reminders not to touch one's face, followed by good hand washing), and tonal changes in verbal expression to make up for the concealed facial expression. We also propose allowing family members of patients with altered mental state to wear transparent face shields during their interactions. Being able to see a familiar face will help to re-orientate the patient and improve communication with their loved ones.

\section{Complicated Grief}

Families of patients who die in hospital during these troubled times are prone to complicated grief. Palliative care teams can support the families by having earlier end-of-life-care discussions, and equip them with knowledge of what to expect in a dying patient. Multidisciplinary teams involving medical social workers, psychologists and religious leaders should be called upon to follow up on grieving families.

\section{Conclusion}

In the midst of caring for patients with COVID-19, we must not forget the needs of the families of non-Covid-19 palliative care patients who are dying in hospitals. They face a unique situation of having to manage their bereavement while trying to navigate through various obstacles from fast-changing hospital policies brought on by the pandemic. Our role as palliative care clinicians is to support them during this crisis.

\section{REFERENCES}

1. Ministry of Health, Singapore. Ministry Of Health Pandemic Readiness And Response Plan For Influenza And Other Acute Respiratory Diseases. Available at: https://www.moh.gov.sg/docs/ librariesprovider5/diseases-updates/interim-pandemic-plan-publicver-_april-2014.pdf. Accessed on 29 May 2020.
2. Ministry of Health, Singapore. Past Updates On COVID-19 Local Situation. Available at: https://www.moh.gov.sg/covid-19/pastupdates. Accessed on 29 May 2020.

3. Government of Singapore. Updates on the COVID-19 situation in Singapore. Available at: https://www.gov.sg/features/covid-19. Accessed on 29 May 2020.

4. Lee GL, Woo IMH, Goh C. Understanding the concept of a "good death" among bereaved family caregivers of cancer patients in Singapore. Palliat Support Care 2013;11:37-46.

5. World Health Organization. WHO definition of Palliative Care. Available at: https://www.who.int/cancer/palliative/definition/en/. Accessed on 29 May 2020.

6. Tan BH, Leo SY, Chew SK. Lessons from the SARS Crisis - More Relevant than Ever. Ann Acad Med Singapore 2006;35:299-300.

7. Leong IY, Lee AO, Ng TW, Lee LB, Koh NY, Yap E, et al. The challenge of providing holistic care in a viral epidemic: opportunities for palliative care. Palliat Med 2004;18:12-8.

8. Bruera E, Sweeney C, Russell N, Willey JS, Palmer JL. Place of death of Houston area residents with cancer over a two-year period. J Pain Symptom Manage 2003;26:637-43.

9. Townsend J, Frank AO, Fermont D, Dyer S, Karran O, Walgrove A, et al. Terminal cancer care and patients' preference for place of death: a prospective study. BMJ 1990;301:415-7.

10. Lee A, Pang WS. Preferred place of death - a local study of cancer patients and their relatives. Singapore Med J 1998;39:447-50.

11. Ozdemir S, Malhotra C, Teo I, Yang GMJ, Kanesvaran R, Yee ACP, et al, Cost of Medical Care of Patients with Advanced Serious Illness in Singapore (COMPASS) Study Group. Palliative Care Awareness Among Advanced Cancer Patients and Their Family Caregivers in Singapore. Ann Acad Med Singapore 2019;48:241-6.

12. Malhotra C, Chan A, Do YK, Malhotra R, Goh C. Good end-of-life care: perspectives of middle-aged and older Singaporeans. J Pain Symptom Manage 2012;44:252-63.

13. Ho CS, Chee CY, Ho RC. Mental Health Strategies to Combat the Psychological Impact of Coronavirus Disease 2019 (COVID-19) Beyond Paranoia and Panic. Ann Acad Med Singapore 2020;49:155-60.

14. Ingravallo F. Death in the era of the COVID-19 pandemic. Lancet Public Health. 2020; 5: e258.

15. Wong CKM, Yip BHK, Mercer S, Griffiths S, Kung K, Wong MC, et al. Effect of facemask on empathy and relational continuity: a randomised controlled trial in primary care. BMC Fam Pract 2013;14:200.

King Jane Ong, ${ }^{1}$ MBBS, MMed Fam Med, PgDip (Pall Med), Michelle Yin Yin Lim, ${ }^{1}$ MBBS, MMed Fam Med, GDPM, Jan Xue Ren Chng, ${ }_{B S C}$ (Hons), MD, GDFM, Yoke Ping Wong, ${ }^{2}{ }_{B S N}, R N$, Lip Hoe $\underline{\text { Koh, }},{ }^{1} M B B S, M R C P(U K), F A M S$

${ }^{1}$ Palliative Care Service, Department of Geriatric Medicine, Changi General Hospital, Singapore

${ }^{2}$ Specialty Nursing (Palliative Care Service), Department of Nursing, Changi General Hospital, Singapore

Address for Correspondence; Dr King Jane Ong, Department of Geriatric Medicine (Palliative Care Service), Changi General Hospital, 2 Simei Street 3, Singapore 529889

Email: jane_ong@cgh.com.sg 